\title{
Pharmacogenomics of human P450 oxidoreductase
}

\author{
Amit V. Pandey ${ }^{1,2 *}$ and Patrick Sproll ${ }^{2}$ \\ 1 Division of Pediatric Endocrinology, Department of Pediatrics, University Children's Hospital Bern, Bern, Switzerland \\ 2 Program in Molecular Life Sciences, Department of Biology, University of Bern, Bern, Switzerland
}

\section{Edited by:}

Kathrin Klein, Dr. Margarete

Fischer-Bosch-Institute of Clinical

Pharmacology and University of

Tübingen, Germany

\section{Reviewed by:}

Chin Eap, University of Lausanne Medical School, Switzerland

Vita Dolzan, University of Ljubljana,

Slovenia

\section{*Correspondence:}

Amit V. Pandey, Division of Pediatric Endocrinology, KIKL C837, University

Children's Hospital Bern,

Freiburgstrasse 15, 3010 Bern,

Switzerland

e-mail: amit@pandeylab.org
Cytochrome P450 oxidoreductase (POR) supports reactions of microsomal cytochrome P450 which metabolize drugs and steroid hormones. Mutations in POR cause disorders of sexual development. P450 oxidoreductase deficiency (PORD) was initially identified in patients with Antley-Bixler syndrome (ABS) but now it has been established as a separate disorder of sexual development (DSD). Here we are summarizing the work on variations in POR related to metabolism of drugs and xenobiotics. We have compiled mutation data on reported cases of PORD from clinical studies. Mutations found in patients with defective steroid profiles impact metabolism of steroid hormones as well as drugs. Some trends are emerging that establish certain founder mutations in distinct populations, with Japanese (R457H), Caucasian (A287P), and Turkish (399-401) populations showing repeated findings of similar mutations. Most other mutations are found as single occurrences. A large number of different variants in POR gene with more than 130 amino acid changes are now listed in databases. Among the polymorphisms, the A503V is found in about $30 \%$ of all alleles but there are some differences across different population groups.

Keywords: P450 oxidoreductase, P450 oxidoreductase deficiency, Antley-Bixler syndrome, steroid metabolism, disorders of sexual development, drug metabolism, P450c17, aromatase

\section{INTRODUCTION}

Cytochrome $\mathrm{P} 450$ reductase (POR) has a major role in metabolism of drugs and steroids (Flück et al., 2007; Pandey and Flück, 2013; Riddick et al., 2013) (Figure 1). All microsomal cytochrome $\mathrm{P} 450$ get electrons from nicotinamide adenine dinucleotide phosphate (NADPH) through POR (Zanger and Schwab, 2013) (Figure 2). A single gene of $71,754 \mathrm{bp}$ located on chromosome 7 (locus 7q11.23) encodes human POR (Table 1). The human POR gene has one non-coding exon and 15 protein-coding exons and encodes a 680 amino acid membrane bound protein (RefSeq protein: NP_000932, UniProt P16435). Disruption of POR affects all microsomal P450 enzyme activities (Flück et al., 2007; Pandey and Flück, 2013). POR also supplies electrons to many other interaction partners. POR knockout mice are embryonic lethal (Shen et al., 2002; Otto et al., 2003). The liver-specific knockout of POR produces mice with lower metabolism and lipid accumulation (Gu et al., 2003; Henderson et al., 2003; Porter et al., 2011).

Cytochrome P450 oxidoreductase deficiency (PORD); (OMIM: 613571 and OMIM: 201750) is a form of congenital adrenal hyperplasia (Flück et al., 2004; Miller et al., 2004; Pandey et al., 2004; Flück and Pandey, 2013). Clinical symptoms of PORD were described in a 46,XY patient with disorder of sexual development (DSD) (Peterson et al., 1985). Sequencing of the POR gene in a Japanese 46,XX girl with a metabolic profile of steroid deficiency and symptoms of Antley-Bixler Syndrome (ABS) led to the characterization of PORD (Flück et al., 2004). Skeletal malformation in many ABS patients with ambiguous genitalia and defective steroid metabolism have now been linked to PORD (Huang et al., 2005). PORD is now listed as a separate metabolic disorder (Huang et al., 2005). An overview of reported cases shows that PORD disrupts steroid biosynthesis in adrenal gland and gonads (Huang et al., 2005; Dhir et al., 2007; Pandey et al., 2007; Flück et al., 2011a). This often leads to genital ambiguity at birth in both male and female. The absence of testosterone (T)/dihydrotestosterone (DHT) leads to development of female external genitalia (Flück and Pandey, in press). The presence of T/DHT triggers the formation of male genitalia. In humans the testosterone is mainly produced in testes by a process that starts by the conversion of pregnenolone to 17-hydroxypregnenolone (17-OHPreg) and dehydroepiandrosterone (DHEA) by the enzyme CYP17A1 in the adrenal (Miller and Auchus, 2011) (Figure 3). Like other microsomal P450 CYP17A1 requires POR (Miller and Auchus, 2011; Pandey and Flück, 2013). Aromatase converts androgens to estrogens and also requires POR (Pandey et al., 2007; Flück et al., 2011a; Bouchoucha et al., 2014). Thus, a defective POR affects sexual development (Flück and Pandey, 2011; Fukami et al., 2013) in both male and female. Many cases still do not have final diagnosis and other genes may be involved (Flück and Pandey, in press). Recently we have reported the first human mutations in aldo-keto reductases AKR1C2 (OMIM: 614279) and AKR1C4 (OMIM: 600451) (Flück et al., 2011b). This established two distinct pathways for the biosynthesis of androgens in fetal testis for control of sexual differentiation between male and female (Flück et al., 2011b; Biason-Lauber et al., 2013a,b; Flück and Pandey, in press). POR also plays a role in this alternate pathway (Biason-Lauber et al., 2013a; Pandey and Flück, 2013) (Figure 3). A large number of POR variants containing more than 130 amino acid changes in the POR protein have now been reported (Figure 4) by multiple researchers, and a list 
of variants in human POR is available at CYP allele website (www.cypalleles.ki.se/por.htm) (Huang et al., 2008; Sim et al., 2009; Flück et al., 2011a; Tomkova et al., 2012).

This review describes current status of information and research on disease related as well as naturally occurring variants of the POR gene. We have collected data on reports of PORD to summarize the current information on effects of POR mutations on enzymatic activities of redox partners. In addition, we have compiled the list of naturally occurring variants in POR gene that have been reported by researchers specifically

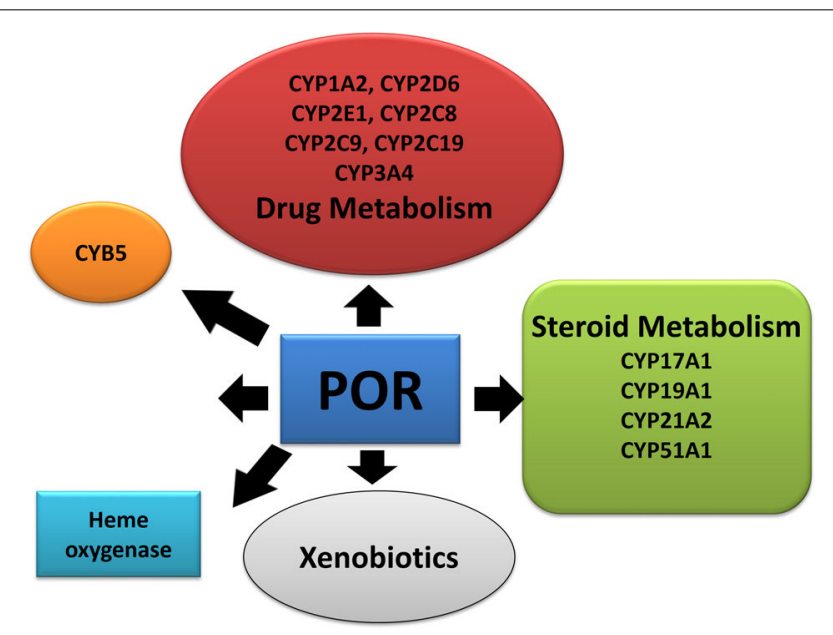

FIGURE 1 | Role of P450 oxidoreductase in biochemical pathways. POR is required for multiple metabolic processes especially the microsomal P450 enzymes involved in metabolism of xenobiotics. sequencing the POR gene in distinct populations. We have also included information on POR variants available in genomic databases from large scale sequencing studies. Recently many POR variants have been studied for effects on drug metabolizing enzymes. We have also summarized studies describing the impact of individual POR variants on in vitro as well as in vivo drug metabolism cytochrome P450 activities. We have labeled the POR variants found in patients with disorders of steroid metabolism as "mutants" and variants identified from normal human population as "polymorphisms" (Figure 4). List of POR variants was compiled from publication of PORD case reports, POR sequencing studies, and human genome sequencing projects available through NCBI databases (http://www.ncbi. nlm.nih.gov).

\section{POR AND STEROID METABOLISM}

PORD was identified as a DSD resulting from disruption of steroid metabolizing cytochrome P450 activities (Flück et al., 2004; Pandey et al., 2004). After the identification of POR variants in normal human population, early reports analyzed the impact of POR variants on three microsomal cytochrome P450 involved in steroid metabolism (CYP17A1, CYP19A1, and CYP21A2) (Flück et al., 2004; Huang et al., 2005; Dhir et al., 2007; Pandey et al., 2007). A large number of POR mutations or polymorphisms (Huang et al., 2005; Flück et al., 2011a) have been studied and analyzed based on known structures of POR (Xia et al., 2011; Pandey and Flück, 2013). Many mutations in POR found in patients are in co-factor binding sites and cause severe POR deficiency. The p.A115V variation first found in patients seems to be a polymorphism (Huang et al., 2008) and shows similar to wild type activity in CYP17A1 assays. The p.T142A mutation

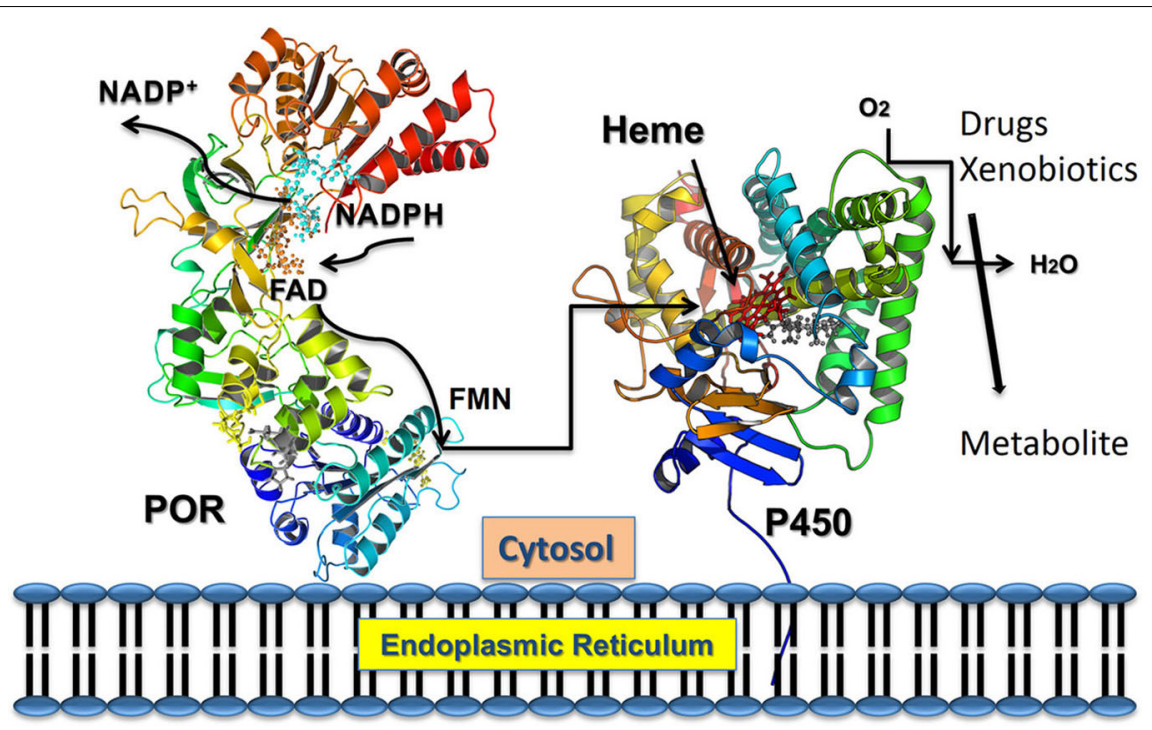

FIGURE 2 | Electron transfer from NADPH to redox partners of POR. NADPH binds to POR located into the endoplasmic reticulum, and donates electrons which are received by FAD. Electron transfer to FAD causes a conformational change that brings together the
FAD and FMN domains and electrons are transferred from FAD to FMN. The FMN domain of POR interacts with the P450s and other redox partners and completes the final step of electron transfer. 
is close to FMN binding site but shows more than 50\% of WT activity (Huang et al., 2005). The mutation p.Q153R also near the FMN binding site, had reduced POR activity in CYP17A1 assays (Table 2 and Figure 5) (Huang et al., 2005). An XY patient of Canadian origin with symptoms of 17-, 21-hydroxylase had POR mutation p.G188_V191dup but enzyme activity data are not available (Krone et al., 2012). The mutation p.A287P is most common in patients from Europe (Huang et al., 2005). It retains 20-40\% of WT activity in CYP17A1 assays (Table 2 ) but had no effect on either CYP19A1 (Flück et al., 2004; Huang et al.,

Table 1 | Database accession numbers for human POR.

\begin{tabular}{ll}
\hline RefSeq Protein & NP_000932 \\
RefSeq RNA & NM_000941 \\
UniGene & Hs.354056 \\
Uniprot & P16435 \\
GenelD & 5447 \\
GeneCards & GC07P075528 \\
Ensembl & ENSG00000127948 \\
HGNC & HGNC:9208 \\
\hline
\end{tabular}

2005; Pandey et al., 2007) or CYP21A2 activity (Dhir et al., 2007). The polymorphism p.R316W shows normal activity in most assays (Huang et al., 2005; Pandey and Flück, 2013). The mutation p.P399_E401del found in two unrelated Turkish families (Flück et al., 2011a) had 68-85\% of WT activity in different P450 assays (Flück et al., 2011a). Polymorphism p.G413S was identified in a sequencing study by Bioventures Inc. (Solus et al., 2004), retains wild type activity in many assays (Table 3) (Huang et al., 2005). A DSD patient of Pakistani origin (17 and 21hydroxylase deficiencies) had p.R498P mutation (Krone et al., 2012). No enzymatic data for p.R498P are available. The variations p.A503V and the p.G504R have $>50 \%$ activity (Huang et al., 2005). A link between p.A503V variant of POR and altered steroid profile in normal population was not found (Utriainen et al., 2012). The mutation p.G539R had $<10 \%$ activity in the 17,20 lyase assay and $46 \%$ activity in the $17 \alpha$-hydroxylase assay (Huang et al., 2005). The mutation p.C569Y in human POR (Flück et al., 2004 ) had $13 \%$ of 17,20 lyase activity and $28 \%$ of $17 \alpha$-hydroxylase activity (Huang et al., 2005). The polymorphism p.R600W has 7$60 \%$ of WT activity in different assays (Huang et al., 2008). The p.C569Y mutation was compound heterozygote together with p.V608F (Flück et al., 2004). The p.V608F retained 57\% of 17,20

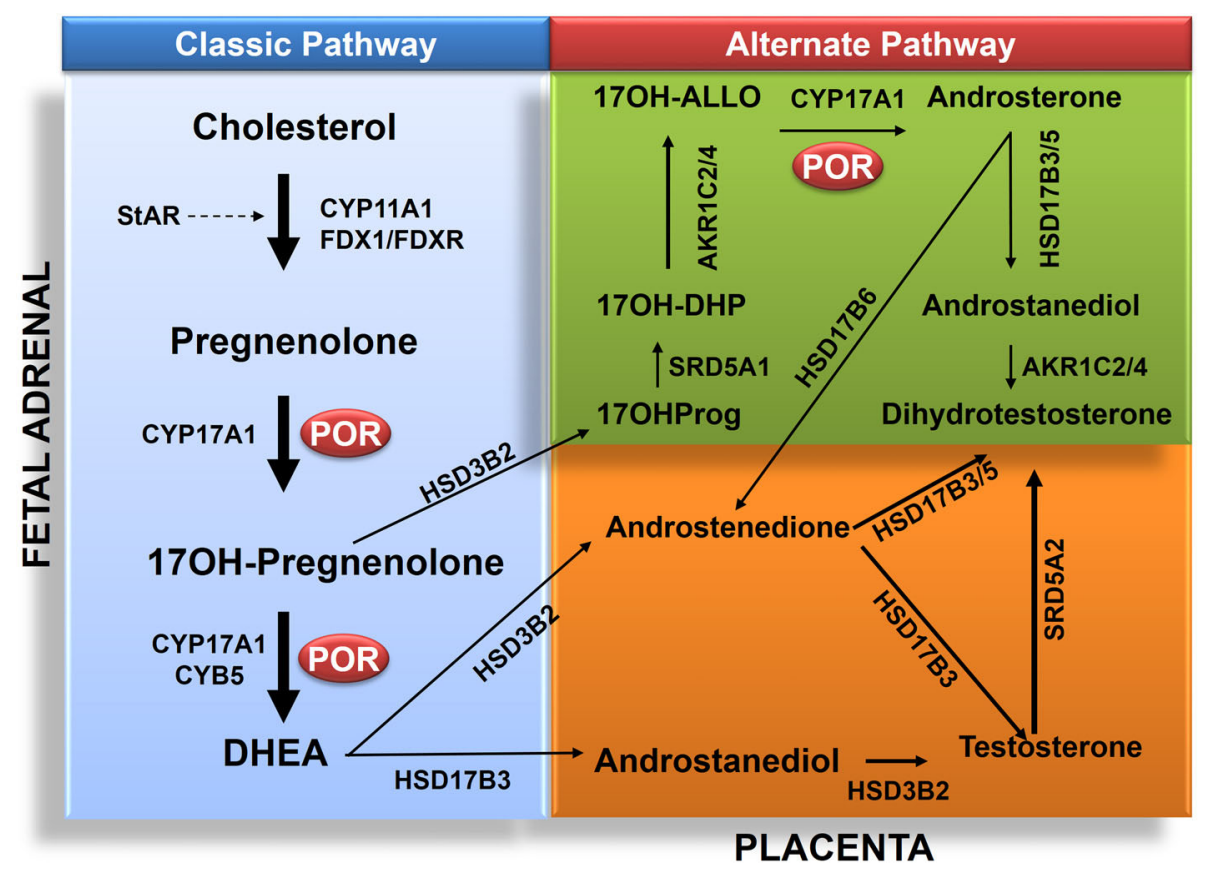

FIGURE 3 | Role of POR in biosynthesis of androgens in classic and alternate pathways. The classic pathway proceeds from transfer cholesterol to mitochondrion through steroidogenic acute regulatory protein (StAR). In the mitochondrion cholesterol is converted to pregnenolone by CYP11A1. The biosynthesis process then continues from pregnenolone to 170 HPreg and DHEA to androstenedione or androstenediol and then to testosterone in testicular Leydig cells. Testosterone (T) is converted to dihydrotesterone (DHT) in genital skin. The backdoor pathway proceeds from 170HPreg to 170HProg, $170 \mathrm{H}-\mathrm{DHP}$, $17 \mathrm{OH}-A$ llo, androsterone, androstanediol (A'diol) and then to DHT in the testis. Abbreviations: CYP11A1, P450scc, cholesterol side-chain cleavage enzyme; StAR, steroidogenic acute regulatory protein; FDX1, Adrenodoxin; FDXR, NADPH adrenodoxin oxidoreductase; CYP17A1,
P450c17, 17 $\alpha$-hydroxylase/17,20-lyase; HSD3B2, 3 $\beta$ HSD2, 3 $\beta$-hydroxysteroid dehydrogenase, type 2; CYB5, cytochrome $b_{5}$; POR, P450 oxidoreductase; HSD17B3, 17 $\beta$ HSD3, 17 -hydroxysteroid dehydrogenase, type 3; and SRD5A2, $5 \alpha$-reductase, type 2. The alternative pathway has four additional enzymes: SRD5A1, $5 \alpha$-reductase, type 1; AKR1C2, Aldo-keto reductase

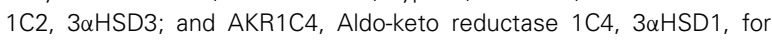
reductive $3 \alpha \mathrm{HSD}$ activity; and HSD17B6, 17 $\beta$ HSD6, 17 $\beta$-hydroxysteroid dehydrogenase, type 6; and/or AKR1C2/4 for oxidative $3 \alpha \mathrm{HSD}$ activity. Full steroid names: 17OHPreg, 17-hydroxypregnenolone; 17OHProg, 17-hydroxyprogesterone; 17OH-DHP, 17-hydroxydihydroprogesterone (5 $\alpha$-pregnan-3 $\alpha, 17 \alpha$-ol-20-one); 17OH-Allo, 17-hydroxyallopregnanolone (5 $\alpha$-pregnan-3 $\alpha, 17 \alpha$-diol-20-one; $\mathrm{P}^{\prime}$ diol); A'diol, androstanediol; T, testosterone; DHT, dihydrotestosterone, DHEA, dehydroepiandrosterone. 


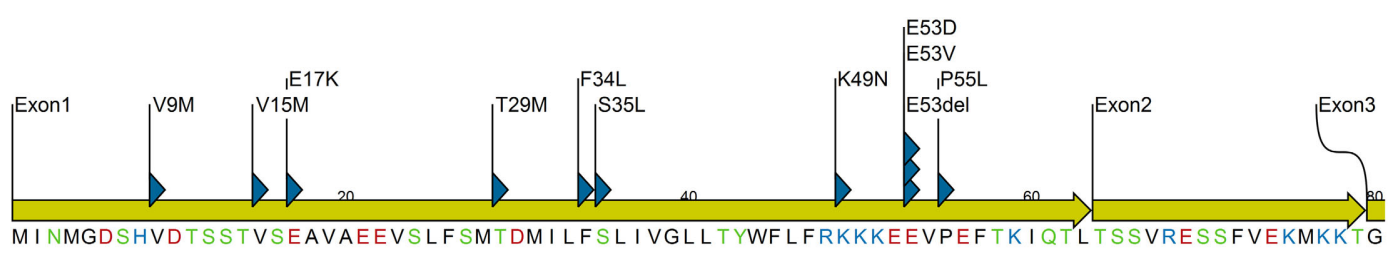

NP_000932 MI NMGDSHVDTSSTVSEAVAEEVSLFSMTDMILFSLIVGLLTYWFLFRKKKEEVPEFTKIQTLTSSVRESSFVEKMKKTG

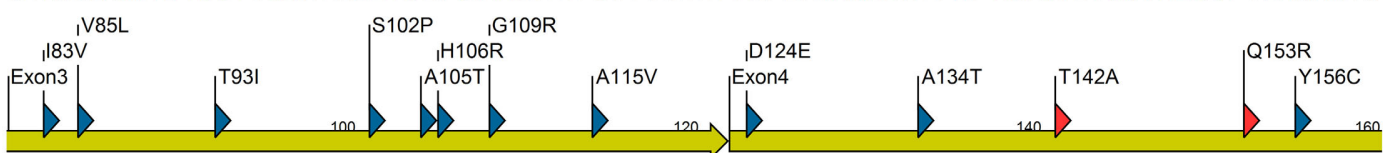

NP_000932 RNI IVFYGSQTGTAEEFANRLSKDAHRYGMRGMSADPEEYDLADLSSLPEIDNALVVFCMATYGEGDPTDNAQDFYDWL $Q$

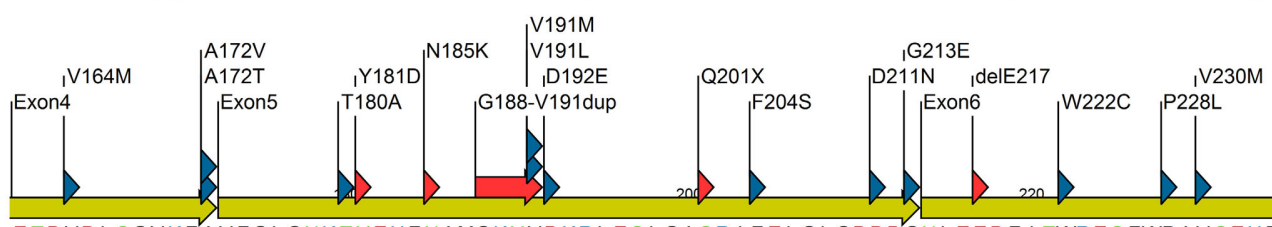

NP_000932 ETDVDLSGVKFAVFGLGNKTYEHFNAMGKYVDKRLEQLGAQR I FELGLGDDDGNLEEDFI TWREQFWPAVCEHFGVEATG

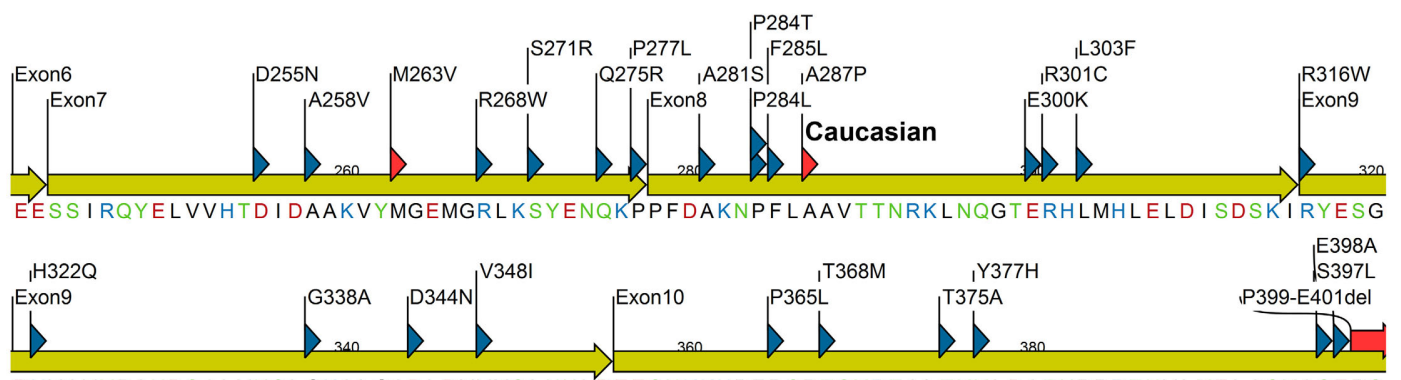

NP_000932 DHVAVYPANDSALVNQLGKI LGADLDVVMSLNNLDEESNKKHPFPCPTSYRTALTYYLDITNPPRTNVLYELAQYASEPS

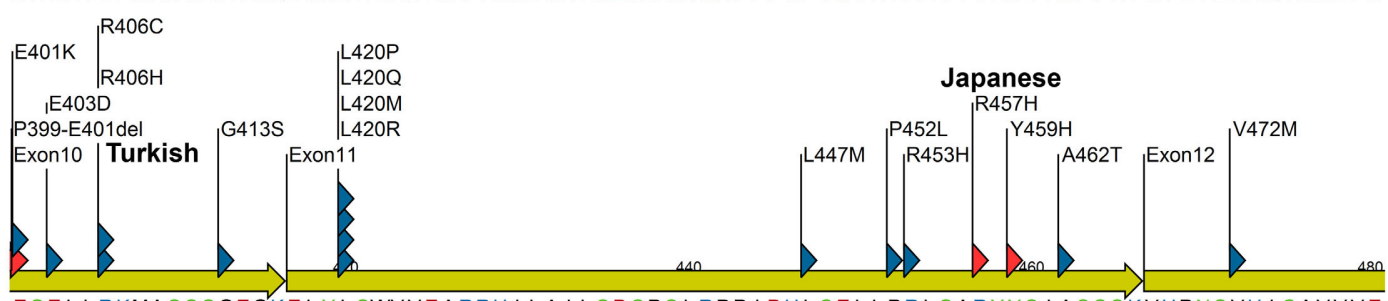

NP_000932 EQELLRKMASSSGEGKELYLSWVVEARRH I LA I LQDCPSLRPP I DHLCELLPRLQARYYSIASSSKVHPNSVH I CAVVVE

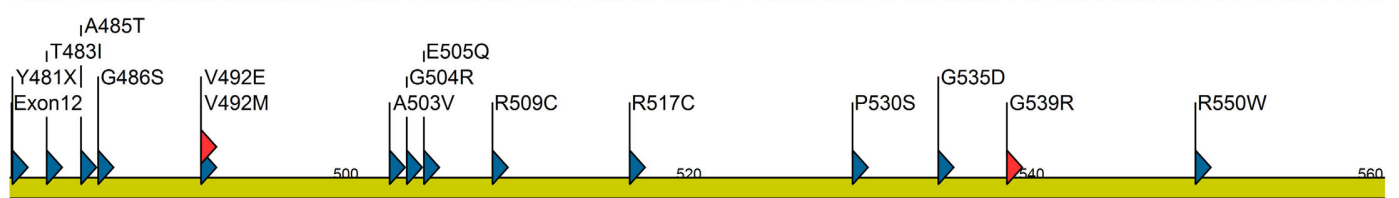

NP_000932 YETKAGR I NKGVATNWLRAKEPAGENGGRALVPMFVRKSQFRLPFKATTPV I MVGPGTGVAPFI GF I QERAWLRQQGKEV

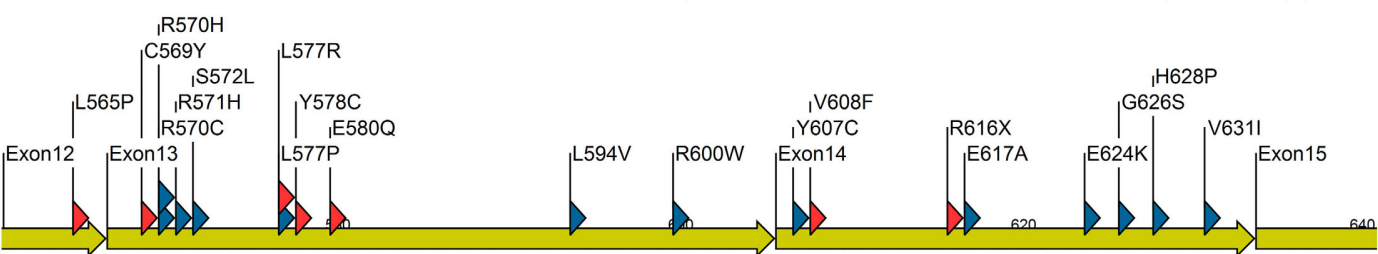

NP_000932 GETLLYYGCRRSDEDYLYREELAQFHRDGALTQLNVAFSREQSHKVYVQHLLKQDREHLWKLIEGGAHI YVCGDARNMAR

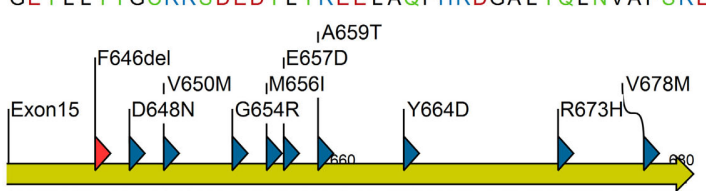

NP_000932 DVQNTFYDIVAELGAMEHAQAVDYIKKLMTKGRYSLDVWS

FIGURE 4 | POR protein sequence showing missense mutations identified in patients and variations from normal human population. Mutation found in patients are indicated with red triangle while variants identified from healthy individuals are indicated with blue triangle. Amino acids are colored based on chemical properties; acidic residues $(D, E)$ are in red, basic residues $(H, R, K)$ are in blue, and rest of the polar amino acids ( $N, C, Q, S, T$, and $Y$ ) are in green. Data were compiled from information available in NCBI SNP database and POR listing at CYPallele database (Sim et al., 2009) as of April 2014. 
Table 2 | Influence of POR variants found in patients with disorder of sexual development, on the enzyme activities of its redox partners.

\begin{tabular}{|c|c|c|c|c|c|c|c|c|c|c|c|}
\hline POR & DBSNP id & CYP3A4 & HO-1 & $\begin{array}{c}\text { Cyt c } \\
\text { red }\end{array}$ & $\begin{array}{c}\text { NADPH } \\
\text { Oxi }\end{array}$ & $\begin{array}{l}\text { CYP17A1 } \\
\text { 170H-ase }\end{array}$ & $\begin{array}{c}\text { CYP17A1 } \\
\text { 17,20 lyase }\end{array}$ & CYP19A1 & CYP1A2 & CYP2C19 & CYP2D6 \\
\hline WT & - & 100 & 100 & 100 & 100 & 100 & 100 & 100 & 100 & 100 & 100 \\
\hline p.Q153R & - & 119 & 72 & 9 & 11 & 31 & 27 & - & 144 & 284 & 128 \\
\hline p.Y181D & rs72552771 & - & - & - & - & - & - & & - & - & \\
\hline p.N185K & & & & 6 & 1 & - & - & & & & \\
\hline p.A287P & rs121912974 & 26 & 49 & 93 & 104 & 40 & 21 & 104 & - & - & - \\
\hline p.P339_E401del & - & & & 20 & & 26 & 31 & & 30 & & \\
\hline p.R457H & rs28931608 & - & - & 1 & - & 3 & - & 1 & - & - & - \\
\hline p.Y459H & - & - & - & - & - & 11 & - & - & - & - & \\
\hline p.V492E & rs28931606 & - & - & - & - & 3 & - & $<1$ & - & - & \\
\hline p.Y607C & rs72557954 & & & - & 20 & 76 & 40 & & 7 & 24 & \\
\hline p.V608F & rs72552772 & 16 & 32 & 8 & 3 & 80 & 57 & 24 & 5 & - & \\
\hline p.R616X & - & - & - & - & 6 & - & - & - & - & - & \\
\hline p.V631I & rs 145782750 & 89 & 96 & 74 & 23 & 51 & 40 & - & 6 & 23 & \\
\hline p.delF646 & - & 88 & 95 & 36 & 94 & 97 & 46 & - & - & - & \\
\hline
\end{tabular}

Activities are shown as percentage of the wild-type POR. POR, P450 oxidoreductase. Data were compiled from previous studies (Flück et al., 2004, 2010, 2011a; Pandey et al., 2004, 2007, 2010; Huang et al., 2005, 2008; Agrawal et al., 2008, 2010; Nicolo et al., 2010; Sandee et al., 2010). The V631/ and Y607C were initially found in patients but later studies established those as normal population variants. Mutations listed in bold abolish all activity. These were found in patients with severe forms of disease and affected residues are located near co-factor binding sites of POR.

Enzymes/reactions and substrates (in parenthesis) listed in this table: CYP3A4: [BOMCC (7-Benzyloxy-4-trifluoromethylcoumarin)]; HO-1: Heme oxygenase-1 (heme); Cyt c red: Cytochrome c reduction (cytochrome c); NADPH ox: NADPH oxidation (NADPH); CYP17A1 17OH-ase: (Progesterone); CYP17A1 17,20 Lyase: (17-hydroxy Pregnenolone), CYP19A1: (androstenedione); CYP1A2, CYP2C19, and CYP2D6: [EOMCC (7-ethoxy-methyloxy-3-cyanocoumarin)].

lyase activity and $80 \%$ of $17 \alpha$-hydroxylase activity (Table 2 and Figure 5) (Huang et al., 2005; Pandey et al., 2007). Both p.C569Y and p.V608F had more severe effects on CYP19A1 activity than on CYP17A1 activities (Flück et al., 2004; Huang et al., 2005; Pandey et al., 2007). The p.H628P affected both CYP17A1 and CYP21A2 activities to similar extent (Dhir et al., 2007). The p.Y607C had greater effects on CYP17A1 and CYP19A1 activities but CYP21A2 activity was $80 \%$ of WT (Idkowiak et al., 2010). There were no severe malformations in the p.Y607C patient (Huang et al., 2005; Idkowiak et al., 2010). A normal steroid profile also suggests normal activities of steroidogenic enzymes in vivo (Idkowiak et al., 2010). The p.V631I retained $40-50 \%$ of activity in the CYP17A1 assays. Deletion of F646 had no effect on 17 $\alpha$-hydroxylase activity but caused a $54 \%$ reduction in 17,20 lyase activity (Huang et al., 2005). Other reported mutants in the region p.Y578C and p.E580Q were not tested in enzymatic assays (Pandey and Flück, 2013).

\section{POR AND DRUG METABOLISM}

After the discovery of POR mutations in patients and identification several variants of POR in healthy individuals we suggested that POR variants may also impact drug metabolizing P450 enzymes since POR is necessary for activities of all microsomal P450 (Flück et al., 2004, 2007; Pandey et al., 2004; Huang et al.,
2005). Variations in POR may affect many different redox partners. Many recent studies reported effects of POR variants on several drug metabolizing P450s (Agrawal et al., 2008, 2010; Hart et al., 2008; Kranendonk et al., 2008; Gomes et al., 2009; Miller et al., 2009; Oneda et al., 2009; Flück et al., 2010; Marohnic et al., 2010; Nicolo et al., 2010; Tomalik-Scharte et al., 2010) and other metabolic processes (Agrawal et al., 2010; Flück et al., 2010; Marohnic et al., 2010; Nicolo et al., 2010; Pandey et al., 2010; Sandee et al., 2010; Zhang et al., 2011). Here we are describing the reports on human studies, an overview of metabolic activities in POR mouse models by laboratories of Roland Wolf and Xin-Xin Ding has been reviewed earlier (Riddick et al., 2013).

Cytochrome P450 3A4 (CYP3A4) metabolizes a wide range of drugs and xenobiotics (Klein and Zanger, 2013; Meyer et al., 2013; Zanger and Schwab, 2013). POR mutations affect CYP3A4 activities in vitro (Nicolo et al., 2010). The POR mutant p.A287P (common mutation found in patients from "European" population) showed $75 \%$ loss of CYP3A4 activity (Table 2 and Figure 6) (Flück et al., 2010; Nicolo et al., 2010). The p.R316W and p.G413S variants had close to WT activities (Flück et al., 2010). The mutations disrupting FAD binding (p.R457H, p.Y459H and p.V492E) resulted in complete loss of CYP3A4 activity (Flück et al., 2010). POR polymorphisms p.A503V and p.G504R showed close to normal activities (Table 3) (Flück et al., 2010). POR 


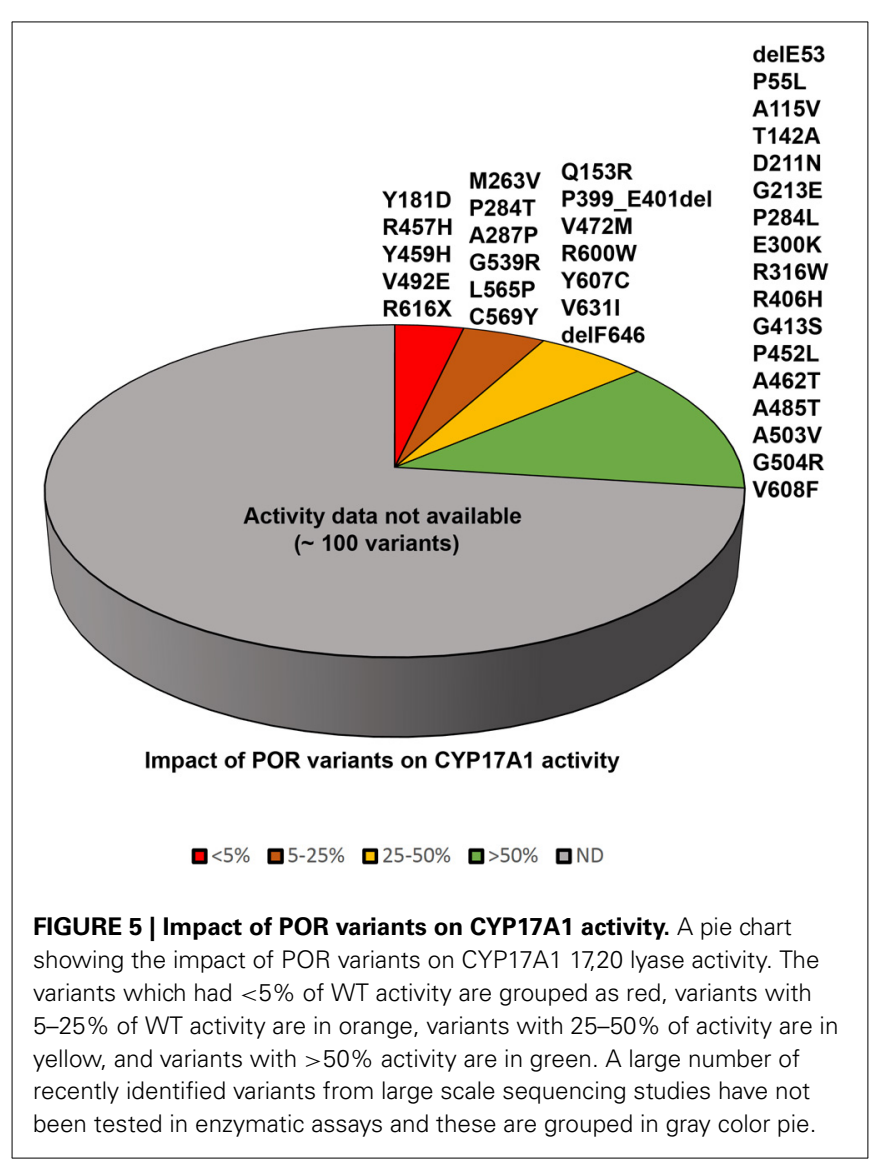

mutations p.C569Y and p.V608F resulted in 65-85\% loss of CYP3A4 and p.R616X lost all activity (Table 2) (Flück et al., 2010). The POR mutant p.Y181D resulted in almost total loss of CYP3A4 activity, while variant p.Q153R was normal and variant p.T142A had 75-80\% activity (Flück et al., 2010). A larger study of POR variants with CYP3A4 suggests POR may change activities of CYP3A4 in patients (Flück et al., 2010; Nicolo et al., 2010). There may be substrate specific effects of POR variants on CYP3A4 activities. Agrawal et al. (2010) found that POR variants p.A287P and p.R457H had lower activity with all substrates. The p.Q153R had 76-94\% of WT activity with midazolam and erythromycin, but showed $129-150 \%$ activity with testosterone and quinidine (Agrawal et al., 2010). The polymorphism p.A503V had $20-40 \%$ reduction in CYP3A4 activity with testosterone and midazolam. With quinidine and erythromycin the p.A503V has no significant change in activities (Agrawal et al., 2010). Studies from us and others have reported normal CYP3A4 activity with POR p.G413S (Flück et al., 2010; Moutinho et al., 2012). POR polymorphisms p.P228L, p.R316W, p.G413S, p.A503V, and p.G504R have $40-100 \%$ activity in most assays (Table 3). The p.A115V had less than $40-60 \%$ of activity, and p.V631I had 23-76\% of wild-type activity (Huang et al., 2005).

Agrawal et al. (2008) found POR mutations p.A287P and p. $\mathrm{R} 457 \mathrm{H}$ resulted in almost complete loss of CYP1A2 and CYP2C19 activities (Table 2). The polymorphism p.A503V had $85 \%$ of WT activity with CYP1A2 and $113 \%$ of WT activity with CYP2C19 (Table 3). The p.Q153R, a disease-linked mutation increased activity of CYP1A2 to $144 \%$ and CYP2C19 activity to $284 \%$ of WT.

In addition to CYP3A4 the CYP2D6 is another major drug metabolizing enzyme (Zanger and Schwab, 2013). POR mutants p.A287P and p.R457H have no CYP2D6 activity with synthetic substrate EOMCC (Sandee et al., 2010). The p.A287P mutant retained $25 \%$ of WT activity with dextromethorphan and bufuralol as CYP2D6 substrates. The p.Q153R had increased activity with CYP2D6. The p.A503V resulted in activities of $85 \%$ with EOMCC, 62\% with dextromethorphan, and 53\% with bufuralol (Sandee et al., 2010).

There may also be differences in effects of POR variants due to presence of $\mathrm{P} 450$ isoforms but, this has not been explored in detail. Subramanian et al. (2012) studied the polymorphic forms of CYP2C9 (CYP2C9.1, CYP2C9.2, and CYP2C9.3) with POR variants. $\mathrm{POR}$ variants p.A287P and p.R457H resulted in reduced activities with all three variants of CYP2C9. The disease related variant p.R153Q had higher activities with all variants of CYP2C9 (Subramanian et al., 2012).

\section{POR VARIANTS IN DIFFERENT GENETIC POPULATIONS}

A study on sequencing of POR gene in 842 healthy people (Huang et al., 2008) detected 140 SNPs, and 43 of those were in $\geq 1 \%$ of alleles. 32 variants were in protein coding regions, 2 in untranslated exon $1 \mathrm{U}, 94$ in the introns and 12 in $5^{\prime}$ flanking DNA. Among the 32 variations in protein coding region, 13 new variants resulted in amino acid change. The new variants were p.delE53, p.P55L, p.D211N, p.G213E, p.P284L, p.P284T, p.R406H, p.P452L, p.A462T, p.V472M, p.A485T, p.R600W, and p.Y607C. The POR polymorphism p.A503V (rs1057868) (Huang et al., 2005), was present in about $25 \%$ of all alleles (Huang et al., 2008). Most of the polymorphic variants had $>40 \%$ of WT activities in different in vitro assays.

Some researchers have attempted to sequence POR gene in human liver samples to study the impact of POR variant in enzymatic studies in liver microsomes. A study of POR sequence in human liver samples by Xiao-Bo Zhong added 3 novel amino acid variations (p.K49N, p.L420M, and p.L577P) (Hart et al., 2008). The POR variant p.L577P had reduced activities in many drug metabolizing P450 assays (Hart et al., 2008). Another study of POR variation analysis by Ulli Zanger in 150 human liver samples found 43 variations with 19 SNPs in exonic regions (Gomes et al., 2009). They also found two combinatorial alleles of (p.P228L + p.A503V and p.A503V + p.V631I) and similar to previous reports, the p.A503V allele was the most common variant (Gomes et al., 2009).

Several new studies have sequenced POR gene in specific population groups. Sequencing of POR gene in 235 Japanese individuals (Saito et al., 2011) found 4 new amino acid changes (p.T29M, p.R550W, p.R570C, and p.A659T). Here p.A503V was present at a somewhat higher frequency of 0.434 . A recent study sequenced POR variants in distinct Jewish populations and identified 6 novel amino acid variants, p.S102P, p.V164M, p.V191M, p.D344N, p.E398A, and p.D648N (Tomkova et al., 2012). The average minor allele frequency (MAF) of p.A503V in different reports have ranged from 0.25 to 0.45 . Analysis of genomic sequence data available at NCBI SNP database shows that there 
Table 3 | Influence of POR variants found in normal population on the enzyme activities of its redox partners.

\begin{tabular}{|c|c|c|c|c|c|c|c|c|c|c|c|}
\hline POR & DBSNP id & CYP3A4 & HO-1 & $\begin{array}{l}\text { Cyt } \\
\text { c red }\end{array}$ & NADPH Ox & $\begin{array}{l}\text { CYP17A1 } \\
\text { 170H-ase }\end{array}$ & $\begin{array}{l}\text { CYP17A1 } \\
\text { 17,20 lyase }\end{array}$ & CYP19A1 & CYP1A2 & CYP2C19 & CYP2D6 \\
\hline WT & - & 100 & 100 & 100 & 100 & 100 & 100 & 100 & 100 & 100 & 100 \\
\hline p.P55L & rs72553988 & & & 67 & 123 & 82 & 115 & & 114 & 83 & \\
\hline p.A115V & rs199634961 & 85 & 95 & 63 & 41 & 80 & 71 & - & - & - & \\
\hline p.P228L & rs17853284 & 101 & 106 & 75 & 72 & 100 & 41 & - & 20 & 39 & \\
\hline p.P284T & rs72557937 & & & 16 & 32 & 14 & 19 & & - & - & \\
\hline p.P284L & rs72557938 & & & 104 & 153 & 44 & 82 & & 41 & 27 & \\
\hline p.E300K & rs11540674 & & & 93 & 104 & 112 & 146 & & 85 & & \\
\hline p.R316W & BV12016\# & 110 & 96 & 61 & 77 & 94 & 141 & - & 109 & 81 & \\
\hline p.V472M & rs72557946 & & & 23 & 24 & 58 & 46 & & 54 & 77 & \\
\hline p.A485T & rs72557947 & & & 36 & 51 & 68 & 88 & & 80 & 98 & \\
\hline p.A503V & rs1057868 & 107 & 97 & 67 & 56 & 68 & 58 & - & 85 & 113 & 85 \\
\hline p.G504R & BV12031\# & 93 & 107 & 53 & 47 & 91 & 103 & - & 82 & 140 & - \\
\hline p.R600W & rs72557950 & & & 67 & 56 & 38 & 40 & & 36 & 60 & \\
\hline p.Y607C & rs72557954 & & & - & 20 & 76 & 40 & & 7 & 24 & \\
\hline p.V631I & rs145782750 & 89 & 96 & 74 & 23 & 51 & 40 & - & 6 & 23 & \\
\hline
\end{tabular}

Activities are shown as percentage of the wild-type POR. POR, P450 oxidoreductase. Data were compiled from previous reports (Flück et al., 2004, 2010, 2011a; Pandey et al., 2004, 2007, 2010; Huang et al., 2005, 2008; Agrawal et al., 2008, 2010; Nicolo et al., 2010; Sandee et al., 2010). \# DBSNP id not available, these were identified in a sequencing study by Bioventures Inc. (Solus et al., 2004) and are represented as Bioventure ID numbers BVxxxxx.

Enzymes/reactions and substrates (in parenthesis) listed in this table: CYP3A4: [BOMCC (7-Benzyloxy-4-trifluoromethylcoumarin)]; HO-1: Heme oxygenase-1 (heme); Cyt c red: Cytochrome c reduction (cytochrome c); NADPH ox: NADPH oxidation (NADPH); CYP17A1 17OH-ase: (Progesterone); CYP17A1 17,20 Lyase: (17-hydroxy Pregnenolone), CYP19A1: (androstenedione); CYP1A2,CYP2C19 and CYP2D6: [EOMCC (7-ethoxy-methyloxy-3-cyanocoumarin)].

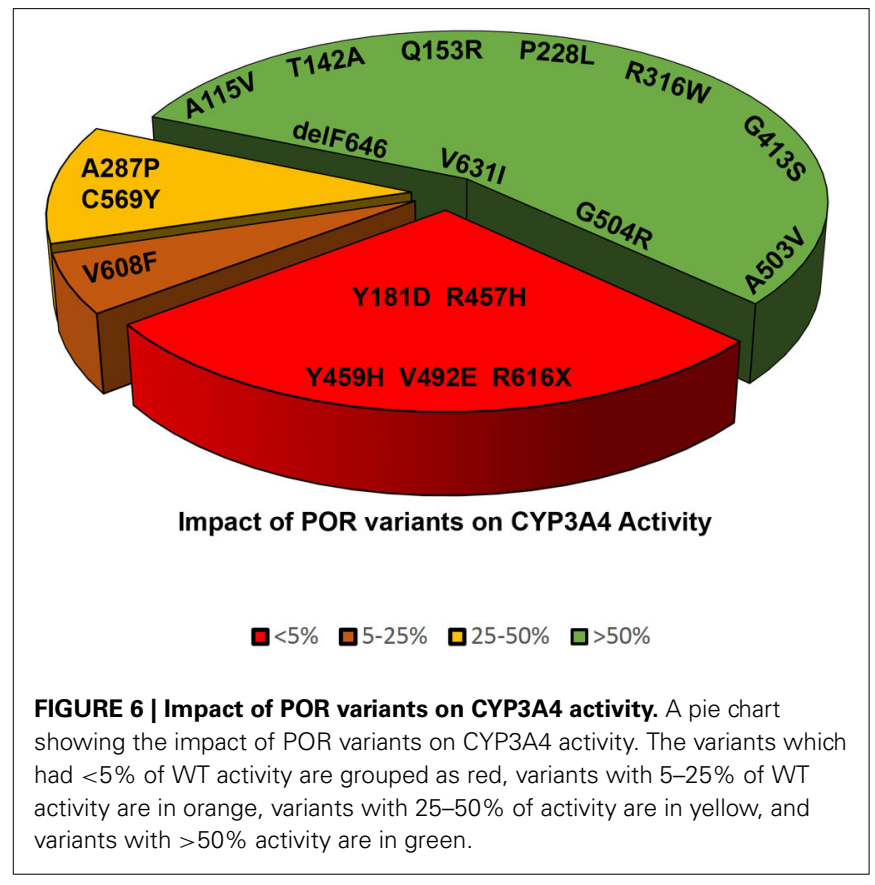

are some differences among different genetic groups (Figure 7). In the Caucasian and Hispanic populations the p.A503V allele frequency is $31 \%$, in Pacific Islanders $34 \%$, and in Asian populations the p.A503V allele is present at $38 \%$. In the Japanese population the p.A503V frequency is highest at $40 \%$ while the African Americans group has the lowest presence at less than $15 \%$ of all alleles. Homozygous presence of p.G5G (rs10262966, nucleotide change GGA to GGG) silent mutation has been associated with increased risk in African Americans (Haiman et al., 2007). This variant is not present in European and Asian populations and has a MAF of 0.023 in Hispanic population (Figure 8). In SubSaharan Africans it is present in 30\% of alleles (MAF 0.297) and African Americans have the highest frequency with $40 \%$ of alleles (MAF 0.400) carrying the p.G5G variant of POR. The p.A50V variant was also tested for association with increased breast cancer risk in same study but no linkage was observed (Haiman et al., 2007).

\section{IN VIVO DRUG CLEARANCE STUDIES EXAMINING THE IMPACT OF POR VARIANTS}

Several studies have now examined the role of POR variants on in vivo drug clearance using many different standard drugs 


\section{rs1057868 (DNA GCC $\rightarrow$ GTG) Amino Acid A503V}

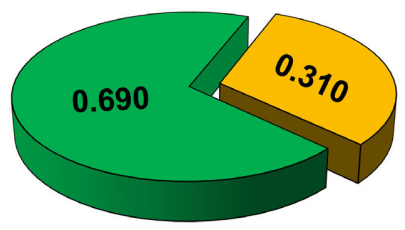

Caucasian

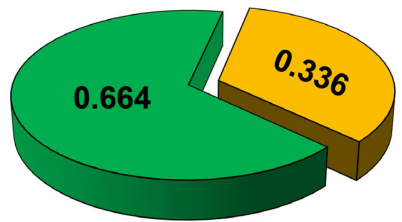

Pacific Islander

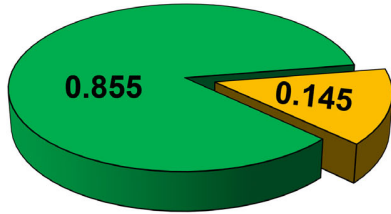

African

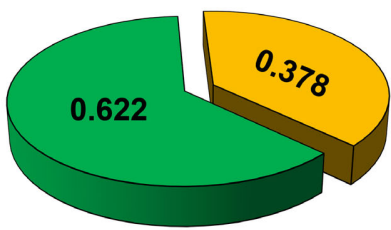

Asian
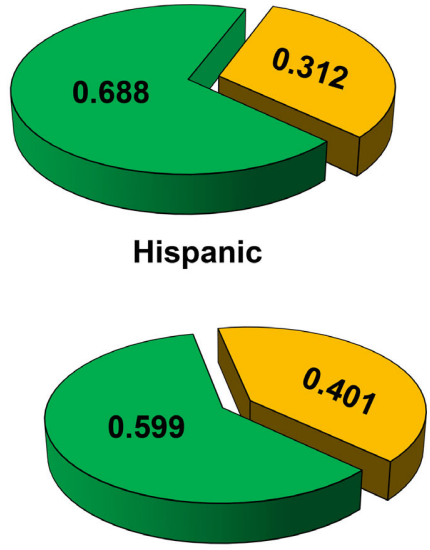

Japanese
FIGURE 7 | Allele frequencies of POR variant A503V in different population groups. The p.A503V variant of POR ( $r$ 1057868) is most common across all population groups. In various sequencing studies specifically targeting POR gene as well as large scale sequencing projects the POR p.A503V is present as most common minor allele. The average minor allele frequency in different studies ranges from 0.25 to 0.45 . A closer look at the data revealed some differences. In the Caucasian and Hispanic populations the p.A503V allele is present in 31\% of alleles, while in Pacific Islanders (34\%) and Asian populations (38\%) there is a slight but consistent increase. In the Japanese population the p.A503V frequency is highest (40\%) while in African Americans it is present in less than $15 \%$ of all alleles. Alleles with p.503A are in green while p.503V is in orange. Data were compiled from information available in NCBI SNP database as of April 2014 (http://www.ncbi.nlm.nih.gov/SNP/snp_ref.cgi?rs=1057868). as markers. One report has described in vivo drug metabolism activities in a POR p.A287P homozygous patient and her heterozygous mother (Tomalik-Scharte et al., 2010). Genotyping of P450 enzymes predicted normal to high P450 activities in both the patient and her mother. The in vivo results showed subnormal activities of CYP1A2, CYP2C9, CYP2D6, and CYP3A4 in the patient. The heterozygous mother had reduced CYP1A2 and CYP2C9 activities. These data are in agreement with disruption of in vitro CYP3A4 activities by p.A287P variant of POR reported by us (Flück et al., 2010; Nicolo et al., 2010). In patients with PORD, the in vitro and in vivo activities of POR dependent $\mathrm{P} 450$ may be taken into account to modify drug dosages and supplementation with steroids.

POR variant p.A503V (POR*28) had higher levels of CYP3A activities based on midazolam clearance (Oneda et al., 2009). Yang et al have studied the effect of POR variant p.A503V on in vivo CYP3A activity in healthy Chinese men (Yang et al., 2011). Out of 73 subjects (CC 21, TT11; CT 41) the midazolam metabolite ratio was greater in the TT group compared with carriers of the C allele. The p.A503V variant of POR had increased 1hydroxylation of midazolam. Further analysis showed association with hepatic but not intestinal CYP3A activities (Yang et al., 2011). There was no significant differences in combined hepatic plus intestinal CYP3A activity.

A study tested the impact of POR p.A503V on metabolism of tacrolimus (de Jonge et al., 2011). They found lower levels of tacrolimus in carriers of p.A503V allele but in the individuals with CYP3A5*3/*3 allele, the p.A503V POR had no effect (de Jonge et al., 2011). Another study measured the impact of p.A503V (rs1057868, DNA change GCC to GTC) allele of POR on metabolism of tacrolimus in healthy Chinese men (Zhang et al., 2013). There was no difference in tacrolimus metabolism between two POR alleles. Further analysis showed no significant differences in tacrolimus pharmacokinetics in CYP3A5 non-expressers $\left(\mathrm{CYP} 3 \mathrm{~A} 5^{*} 3 /^{*} 3\right)$. The mean tacrolimus exposure for the p.A503V CC homozygotes in CYP3A5 expressers (CYP3A $5 * 1 /{ }^{*} 1$ or $* 1 /{ }^{*} 3$ ) were much higher than the p.A503V CT heterozygotes. These studies suggest a role for p.A503V allele of POR in the variability of tacrolimus exposure levels. In vitro studies of CYP3A5 activities comparing normal and p.A503V variants of POR may confirm this hypothesis.

A CYP1A2 genotyping study in smokers also checked POR polymorphic variants for potential linkage to metabolic defects (Dobrinas et al., 2012). During smoking there was no impact of any POR polymorphisms on CYP1A2 activity. CYP1A2 activity increased after smoking cessation in POR rs2302429A and rs1057868T (p.A503V) carriers. The carriers of POR rs2286823A and of rs17148944G-rs10239977Crs3815455C-rs2286823A-rs2302429G-rs1057868C (503A) had decreased CYP1A2 activity.

\section{CONCLUSIONS}

PORD is more complex than any single enzyme or protein deficiency (Janner et al., 2006; Flück et al., 2011c; Camats et al., 2012). It affects drug and xenobiotic metabolism pathways (Henderson et al., 2006; Flück et al., 2010; Nicolo et al., 2010). Variants of POR have different interactions with different redox partners. Effect of POR variants on drug metabolizing P450 enzymes needs detailed studies. Deposition of heme in liver lowers cytochrome P450 levels and enzymatic activities (Pandey et al., 1995, 1996). 


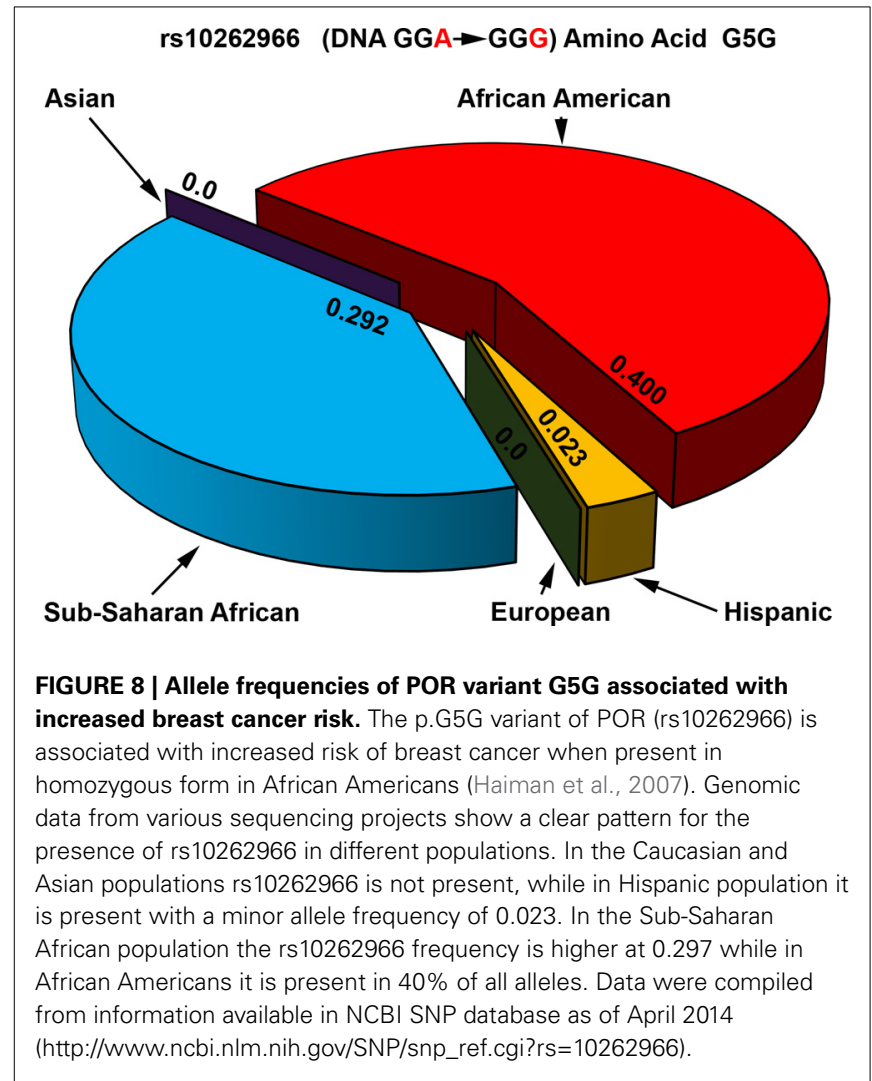

POR variants with lower activities may complicate these symptoms and result in a more severe disease. Heme oxygenase plays a major role in limiting the severity of malaria and sepsis infections (Pamplona et al., 2007; Larsen et al., 2010; Pandey et al., 2010; Ferreira et al., 2011). There may be potential links between the common POR variants and pathogenesis of infections. External flavin supplementation reverts loss of activity of some POR variants (Nicolo et al., 2010). An interesting possibility to explore in future experiments is whether external FMN can receive electrons from bound NADPH in POR as reported for a $B$. subtilis reductase (Deller et al., 2006). Whether flavin treatment may help patients with POR deficiency remains untested in clinical settings.

\section{ACKNOWLEDGMENTS}

This work has been supported by grants to Amit V. Pandey from the Swiss National Science Foundation (31003A-134926), Schweizerischen Mobiliar Genossenschaft Jubiläumsstiftung and Bern University Research Foundation.

\section{REFERENCES}

Agrawal, V., Choi, J. H., Giacomini, K. M., and Miller, W. L. (2010). Substrate-specific modulation of CYP3A4 activity by genetic variants of cytochrome P450 oxidoreductase. Pharmacogenet. Genomics 20, 611-618. doi: 10.1097/FPC.0b013e32833e0cb5

Agrawal, V., Huang, N., and Miller, W. L. (2008). Pharmacogenetics of P450 oxidoreductase: effect of sequence variants on activities of CYP1A2 and CYP2C19. Pharmacogenet. Genomics 18, 569-576. doi: 10.1097/FPC.0b013e32830054ac

Biason-Lauber, A., Miller, W. L., Pandey, A. V., and Flück, C. E. (2013a). Of marsupials and men: "Backdoor" dihydrotestosterone synthesis in male sexual differentiation. Mol. Cell. Endocrinol. 371, 124-132. doi: 10.1016/j.mce.2013.01.017
Biason-Lauber, A., Pandey, A. V., Miller, W. L., and Flück, C. E. (2013b). “Marsupial pathways in humans," in Genetic Steroid Disorders, eds M. I. New, O. Lekarev, A. Parsa, T. Yuen, B. O’Mally, and G. Hammer (New York, NY: Academic Press), 215-224.

Bouchoucha, N., Samara-Boustani, D., Pandey, A. V., Bony-Trifunovic, H., Hofer, G., Aigrain, Y., et al. (2014). Characterization of a novel CYP19A1 (aromatase) $\mathrm{R} 192 \mathrm{H}$ mutation causing virilization of a 46,XX newborn, undervirilization of the 46, XY brother, but no virilization of the mother during pregnancies. Mol. Cell. Endocrinol. 390, 8-17. doi: 10.1016/j.mce.2014.03.008

But, W. M., Lo, I. F., Shek, C. C., Tse, W. Y., and Lam, S. T. (2010). Ambiguous genitalia, impaired steroidogenesis, and Antley-Bixler syndrome in a patient with P450 oxidoreductase deficiency. Hong Kong Med. J. 16, 59-62. Available online at: http://www.hkmj.org/article_pdfs/hkm1002p59.pdf

Camats, N., Pandey, A. V., Fernandez-Cancio, M., Andaluz, P., Janner, M., Toran, N., et al. (2012). Ten novel mutations in the NR5Al gene cause disordered sex development in 46, XY and ovarian insufficiency in 46, XX individuals. J. Clin. Endocrinol. Metab. 97, E1294-E1306. doi: 10.1210/jc.2011-3169

de Jonge, H., Metalidis, C., Naesens, M., Lambrechts, D., and Kuypers, D. R. (2011). The $\mathrm{P} 450$ oxidoreductase * $28 \mathrm{SNP}$ is associated with low initial tacrolimus exposure and increased dose requirements in CYP3A5-expressing renal recipients. Pharmacogenomics 12, 1281-1291. doi: 10.2217/pgs.11.77

Deller, S., Sollner, S., Trenker-El-Toukhy, R., Jelesarov, I., Gubitz, G. M., and Macheroux, P. (2006). Characterization of a thermostable NADPH:FMN oxidoreductase from the mesophilic bacterium Bacillus subtilis. Biochemistry 45, 7083-7091. doi: 10.1021/bi052478r

Dhir, V., Ivison, H. E., Krone, N., Shackleton, C. H., Doherty, A. J., Stewart, P. M., et al. (2007). Differential inhibition of CYP17A1 and CYP21A2 activities by the P450 oxidoreductase mutant A287P. Mol. Endocrinol. 21, 1958-1968. doi: 10.1210/me.2007-0066

Dobrinas, M., Cornuz, J., Pedrido, L., and Eap, C. B. (2012). Influence of cytochrome P450 oxidoreductase genetic polymorphisms on CYP1A2 activity and inducibility by smoking. Pharmacogenet. Genomics 22, 143-151. doi: 10.1097/FPC.0b013e32834e9ela

Ferreira, A., Marguti, I., Bechmann, I., Jeney, V., Chora, A., Palha, N. R., et al. (2011). Sickle hemoglobin confers tolerance to Plasmodium infection. Cell 145, 398-409. doi: 10.1016/j.cell.2011.03.049

Flück, C. E., Mallet, D., Hofer, G., Samara-Boustani, D., Leger, J., Polak, M., et al. (2011a). Deletion of P399_E401 in NADPH cytochrome P450 oxidoreductase results in partial mixed oxidase deficiency. Biochem. Biophys. Res. Commun. 412, 572-577. doi: 10.1016/j.bbrc.2011.08.001

Flück, C. E., Meyer-Böni, M., Pandey, A. V., Kempna, P., Miller, W. L., Schoenle, E. J., et al. (2011b). Why boys will be boys: two pathways of fetal testicular androgen biosynthesis are needed for male sexual differentiation. Am. J. Hum. Genet. 89, 201-218. doi: 10.1016/j.ajhg.2011.06.009

Flück, C. E., Mullis, P. E., and Pandey, A. V. (2010). Reduction in hepatic drug metabolizing CYP3A4 activities caused by $\mathrm{P} 450$ oxidoreductase mutations identified in patients with disordered steroid metabolism. Biochem. Biophys. Res. Commun. 401, 149-153. doi: 10.1016/j.bbrc.2010.09.035

Flück, C. E., Nicolo, C., and Pandey, A. V. (2007). Clinical, structural and functional implications of mutations and polymorphisms in human NADPH P450 oxidoreductase. Fundam. Clin. Pharmacol. 21, 399-410. doi: 10.1111/j.14728206.2007.00520.x

Flück, C. E., and Pandey, A. V. (2011). Clinical and biochemical consequences of p450 oxidoreductase deficiency. Endocr. Dev. 20, 63-79. doi: 10.1159/000321221

Flück, C. E., and Pandey, A. V. (2013). "P450 oxidoreductase deficiency (PORD)," in Genetic Steroid Disorders, eds M. I. New, O. Lekarev, A. Parsa, T. Yuen, B. O'Mally, and G. Hammer (New York, NY: Academic Press), 125-143.

Flück, C. E., and Pandey, A. V. (in press). Steroidogenesis of the testis - new genes and pathways. Ann. Endocrinol. doi: 10.1016/j.ando.2014.03.002

Flück, C. E., Pandey, A. V., Dick, B., Camats, N., Fernandez-Cancio, M., Clemente, M., et al. (2011c). Characterization of novel StAR (Steroidogenic Acute Regulatory Protein) mutations causing non-classic lipoid adrenal hyperplasia. PLoS ONE 6:e20178. doi: 10.1371/journal.pone.0020178

Flück, C. E., Tajima, T., Pandey, A. V., Arlt, W., Okuhara, K., Verge, C. F., et al. (2004). Mutant P450 oxidoreductase causes disordered steroidogenesis with and without Antley-Bixler syndrome. Nat. Genet. 36, 228-230. doi: 10.1038/ng1300

Fukami, M., Homma, K., Hasegawa, T., and Ogata, T. (2013). Backdoor pathway for dihydrotestosterone biosynthesis: implications for normal and abnormal human sex development. Dev. Dyn. 242, 320-329. doi: 10.1002/dvdy.23892 
Gomes, A. M., Winter, S., Klein, K., Turpeinen, M., Schaeffeler, E., Schwab, M., et al. (2009). Pharmacogenomics of human liver cytochrome P450 oxidoreductase: multifactorial analysis and impact on microsomal drug oxidation. Pharmacogenomics 10, 579-599. doi: 10.2217/pgs.09.7

Gu, J., Weng, Y., Zhang, Q. Y., Cui, H., Behr, M., Wu, L., et al. (2003). Liverspecific deletion of the NADPH-cytochrome $\mathrm{P} 450$ reductase gene: impact on plasma cholesterol homeostasis and the function and regulation of microsomal cytochrome P450 and heme oxygenase. J. Biol. Chem. 278, 25895-25901. doi: 10.1074/jbc.M303125200

Haiman, C. A., Setiawan, V. W., Xia, L. Y., Le Marchand, L., Ingles, S. A., Ursin, G., et al. (2007). A variant in the cytochrome p450 oxidoreductase gene is associated with breast cancer risk in African Americans. Cancer Res. 67, 3565-3568. doi: 10.1158/0008-5472.CAN-06-4801

Hart, S. N., Wang, S., Nakamoto, K., Wesselman, C., Li, Y., and Zhong, X. B. (2008). Genetic polymorphisms in cytochrome $\mathrm{P} 450$ oxidoreductase influence microsomal P450-catalyzed drug metabolism. Pharmacogenet. Genomics 18, 11-24. doi: 10.1097/FPC.0b013e3282f2f121

Henderson, C. J., Otto, D. M., Carrie, D., Magnuson, M. A., McLaren, A. W., Rosewell, I., et al. (2003). Inactivation of the hepatic cytochrome P450 system by conditional deletion of hepatic cytochrome P450 reductase. J. Biol. Chem. 278, 13480-13486. doi: 10.1074/jbc.M212087200

Henderson, C. J., Pass, G. J., and Wolf, C. R. (2006). The hepatic cytochrome P450 reductase null mouse as a tool to identify a successful candidate entity. Toxicol. Lett. 162, 111-117. doi: 10.1016/j.toxlet.2005.10.016

Herkert, J. C., Blaauwwiekel, E. E., Hoek, A., Veenstra-Knol, H. E., Kema, I. P., Arlt, W., et al. (2011). A rare cause of congenital adrenal hyperplasia: Antley-Bixler syndrome due to POR deficiency. Neth. J. Med. 69, 281-283. Available online at: http://www.njmonline.nl/getpdf.php?t=a\&id=10000734

Huang, N., Agrawal, V., Giacomini, K. M., and Miller, W. L. (2008). Genetics of P450 oxidoreductase: sequence variation in 842 individuals of four ethnicities and activities of 15 missense mutations. Proc. Natl. Acad. Sci. U.S.A. 105, 1733-1738. doi: 10.1073/pnas.0711621105

Huang, N., Pandey, A. V., Agrawal, V., Reardon, W., Lapunzina, P. D., Mowat, D., et al. (2005). Diversity and function of mutations in p450 oxidoreductase in patients with Antley-Bixler syndrome and disordered steroidogenesis. Am. J. Hum. Genet. 76, 729-749. doi: 10.1086/429417

Idkowiak, J., Malunowicz, E. M., Dhir, V., Reisch, N., Szarras-Czapnik, M., Holmes, D. M., et al. (2010). Concomitant mutations in the P450 oxidoreductase and androgen receptor genes presenting with 46,XY disordered sex development and androgenization at adrenarche. J. Clin. Endocrinol. Metab. 95, 3418-3427. doi: 10.1210/jc.2010-0058

Janner, M., Pandey, A. V., Mullis, P. E., and Flück, C. E. (2006). Clinical and biochemical description of a novel CYP21A2 gene mutation 962_963insA using a new 3D model for the P450c21 protein. Eur. J. Endocrinol. 155, 143-151. doi: 10.1530/eje.1.02172

Klein, K., and Zanger, U. M. (2013). Pharmacogenomics of cytochrome P450 3A4: recent progress toward the "Missing Heritability" problem. Front. Genet. 4:12. doi: 10.3389/fgene.2013.00012

Ko, J. M., Cheon, C. K., Kim, G. H., and Yoo, H. W. (2009). A case of Antley-Bixler syndrome caused by compound heterozygous mutations of the cytochrome P450 oxidoreductase gene. Eur. J. Pediatr. 168, 877-880. doi: 10.1007/s00431008-0849-0

Kranendonk, M., Marohnic, C. C., Panda, S. P., Duarte, M. P., Oliveira, J. S., Masters, B. S., et al. (2008). Impairment of human CYP1A2-mediated xenobiotic metabolism by Antley-Bixler syndrome variants of cytochrome P450 oxidoreductase. Arch. Biochem. Biophys. 475, 93-99. doi: 10.1016/j.abb.2008. 04.014

Krone, N., Reisch, N., Idkowiak, J., Dhir, V., Ivison, H. E., Hughes, B. A., et al. (2012). Genotype-phenotype analysis in congenital adrenal hyperplasia due to P450 oxidoreductase deficiency. J. Clin. Endocrinol. Metab. 97, E257-E267. doi: 10.1210/jc.2011-0640

Larsen, R., Gozzelino, R., Jeney, V., Tokaji, L., Bozza, F. A., Japiassu, A. M., et al. (2010). A central role for free heme in the pathogenesis of severe sepsis. Sci. Transl. Med. 2, 51ra71. doi: 10.1126/scitranslmed.3001118

Marohnic, C. C., Panda, S. P., McCammon, K., Rueff, J., Masters, B. S., and Kranendonk, M. (2010). Human cytochrome P450 oxidoreductase deficiency caused by the Y181D mutation: molecular consequences and rescue of defect. Drug Metab. Dispos. 38, 332-340. doi: 10.1124/dmd.109.030445
Meyer, U. A., Zanger, U. M., and Schwab, M. (2013). Omics and drug response. Annu. Rev. Pharmacol. Toxicol. 53, 475-502. doi: 10.1146/annurev-pharmtox010510-100502

Miller, W. L., and Auchus, R. J. (2011). The molecular biology, biochemistry, and physiology of human steroidogenesis and its disorders. Endocr. Rev. 32, 81-151. doi: 10.1210/er.2010-0013

Miller, W. L., Huang, N., Agrawal, V., and Giacomini, K. M. (2009). Genetic variation in human P450 oxidoreductase. Mol. Cell. Endocrinol. 300, 180-184. doi: 10.1016/j.mce.2008.09.017

Miller, W. L., Huang, N., Flück, C. E., and Pandey, A. V. (2004). P450 oxidoreductase deficiency. Lancet 364, 1663. doi: 10.1016/S0140-6736(04)17344-3

Moutinho, D., Marohnic, C. C., Panda, S. P., Rueff, J., Masters, B. S., and Kranendonk, M. (2012). Altered human CYP3A4 activity caused by AntleyBixler syndrome-related variants of NADPH-cytochrome P450 oxidoreductase measured in a robust in vitro system. Drug Metab. Dispos. 40, 754-760. doi: 10.1124/dmd.111.042820

Nicolo, C., Flück, C. E., Mullis, P. E., and Pandey, A. V. (2010). Restoration of mutant cytochrome P450 reductase activity by external flavin. Mol. Cell. Endocrinol. 321, 245-252. doi: 10.1016/j.mce.2010.02.024

Oneda, B., Crettol, S., Jaquenoud Sirot, E., Bochud, M., Ansermot, N., and Eap, C. B. (2009). The P450 oxidoreductase genotype is associated with CYP3A activity in vivo as measured by the midazolam phenotyping test. Pharmacogenet. Genomics 19, 877-883. doi: 10.1097/FPC.0b013e32833225e7

Otto, D. M., Henderson, C. J., Carrie, D., Davey, M., Gundersen, T. E., Blomhoff, R., et al. (2003). Identification of novel roles of the cytochrome P450 system in early embryogenesis: effects on vasculogenesis and retinoic acid homeostasis. Mol. Cell. Biol. 23, 6103-6116. doi: 10.1128/MCB.23.17.6103-6116.2003

Pamplona, A., Ferreira, A., Balla, J., Jeney, V., Balla, G., Epiphanio, S., et al. (2007). Heme oxygenase-1 and carbon monoxide suppress the pathogenesis of experimental cerebral malaria. Nat. Med. 13, 703-710. doi: 10.1038/nm1586

Pandey, A. V., and Flück, C. E. (2013). NADPH P450 oxidoreductase: structure, function, and pathology of diseases. Pharmacol. Ther. 138, 229-254. doi: 10.1016/j.pharmthera.2013.01.010

Pandey, A. V., Flück, C. E., Huang, N., Tajima, T., Fujieda, K., and Miller, W. L. (2004). P450 oxidoreductase deficiency: a new disorder of steroidogenesis affecting all microsomal P450 enzymes. Endocr. Res. 30, 881-888. doi: 10.1081/ERC-200044134

Pandey, A. V., Flück, C. E., and Mullis, P. E. (2010). Altered heme catabolism by heme oxygenase-1 caused by mutations in human NADPH cytochrome P450 reductase. Biochem. Biophys. Res. Commun. 400, 374-378. doi: 10.1016/j.bbrc.2010.08.072

Pandey, A. V., Kempna, P., Hofer, G., Mullis, P. E., and Flück, C. E. (2007). Modulation of human CYP19A1 activity by mutant NADPH P450 oxidoreductase. Mol. Endocrinol. 21, 2579-2595. doi: 10.1210/me.2007-0245

Pandey, A. V., Tekwani, B. L., and Pandey, V. C. (1995). Characterization of hemozoin from liver and spleen of mice infected with Plasmodium yoelli, a rodent malaria parasite. Biomed. Res. Tokyo 16, 115-120.

Pandey, A. V., Tekwani, B. L., and Pandey, V. C. (1996). Effect of Plasmodium yoelii infection on constitutive and phenobarbitone inducible mixed function oxidase system of mice. J. Parasitic Dis. 20, 141-144.

Peterson, R. E., Imperato-McGinley, J., Gautier, T., and Shackleton, C. H. L. (1985). Male pseudohermaphroditism due to multiple defects in steroid-biosynthetic microsomal mixed-function oxidases. A new variant of congenital adrenal hyperplasia. N. Engl. J. Med. 313, 1182-1191. doi: 10.1056/NEJM198511073131903

Porter, T. D., Banerjee, S., Stolarczyk, E. I., and Zou, L. (2011). Suppression of cytochrome P450 reductase (POR) expression in hepatoma cells replicates the hepatic lipidosis observed in hepatic POR-null mice. Drug Metab. Dispos. 39, 966-973. doi: 10.1124/dmd.111.038562

Puiu, M., Pienar, C., Emandi, A. C., Arghirescu, S., Popa, C., and Micle, I. (2012). A case of Antley Bixler syndrome: diagnosis and outcome. Acta Endocrinol. Buch. 8, 479-484. doi: 10.4183/aeb.2012.479

Riddick, D. S., Ding, X., Wolf, C. R., Porter, T. D., Pandey, A. V., Zhang, Q. Y., et al. (2013). NADPH-cytochrome P450 oxidoreductase: roles in physiology, pharmacology, and toxicology. Drug Metab. Dispos. 41, 12-23. doi: 10.1124/dmd.112.048991

Saito, Y., Yamamoto, N., Katori, N., Maekawa, K., Fukushima-Uesaka, H., Sugimoto, D., et al. (2011). Genetic polymorphisms and haplotypes of por, 
encoding cytochrome p450 oxidoreductase, in a Japanese population. Drug Metab. Pharmacokinet. 26, 107-116. doi: 10.2133/dmpk.DMPK-10-SC-096

Sandee, D., Morrissey, K., Agrawal, V., Tam, H. K., Kramer, M. A., Tracy, T. S., et al. (2010). Effects of genetic variants of human P450 oxidoreductase on catalysis by CYP2D6 in vitro. Pharmacogenet. Genomics 20, 677-686. doi 10.1097/FPC.0b013e32833f4f9b

Shen, A. L., O'Leary, K. A., and Kasper, C. B. (2002). Association of multiple developmental defects and embryonic lethality with loss of microsomal NADPH-cytochrome P450 oxidoreductase. J. Biol. Chem. 277, 6536-6541. doi: 10.1074/jbc.M111408200

Sim, S. C., Miller, W. L., Zhong, X. B., Arlt, W., Ogata, T., Ding, X., et al. (2009). Nomenclature for alleles of the cytochrome P450 oxidoreductase gene. Pharmacogenet. Genomics 19, 565-566. doi: 10.1097/FPC.0b013e32832af5b7

Solus, J. F., Arietta, B. J., Harris, J. R., Sexton, D. P., Steward, J. Q., McMunn, C., et al. (2004). Genetic variation in eleven phase I drug metabolism genes in an ethnically diverse population. Pharmacogenomics 5, 895-931. doi: 10.1517/14622416.5.7.895

Subramanian, M., Agrawal, V., Sandee, D., Tam, H. K., Miller, W. L., and Tracy, T. S. (2012). Effect of P450 oxidoreductase variants on the metabolism of model substrates mediated by CYP2C9.1, CYP2C9.2, and CYP2C9.3. Pharmacogenet. Genomics 22, 590-597. doi: 10.1097/FPC.0b013e3283544062

Tomalik-Scharte, D., Maiter, D., Kirchheiner, J., Ivison, H. E., Fuhr, U., and Arlt, W. (2010). Impaired hepatic drug and steroid metabolism in congenital adrenal hyperplasia due to P450 oxidoreductase deficiency. Eur. J. Endocrinol. 163, 919-924. doi: 10.1530/EJE-10-0764

Tomkova, M., Marohnic, C. C., Gurwitz, D., Seda, O., Masters, B. S., and Martasek, P. (2012). Identification of six novel P450 oxidoreductase missense variants in Ashkenazi and Moroccan Jewish populations. Pharmacogenomics 13, 543-554. doi: $10.2217 /$ pgs. 12.21

Utriainen, P., Laakso, S., Jaaskelainen, J., and Voutilainen, R. (2012). Polymorphisms of POR, SULT2A1 and HSD11B1 in children with premature adrenarche. Metabolism 61, 1215-1219. doi: 10.1016/j.metabol.2012.02.008

Xia, C., Panda, S. P., Marohnic, C. C., Martasek, P., Masters, B. S., and Kim, J. J. (2011). Structural basis for human NADPH-cytochrome P450 oxidoreductase deficiency. Proc. Natl. Acad. Sci. U.S.A. 108, 13486-13491. doi: 10.1073/pnas. 1106632108

Yang, G., Fu, Z., Chen, X., Yuan, H., Yang, H., Huang, Y., et al. (2011). Effects of the CYP oxidoreductase Ala503Val polymorphism on CYP3A activity in vivo: a randomized, open-label, crossover study in healthy Chinese men. Clin. Ther. 33, 2060-2070. doi: 10.1016/j.clinthera.2011.11.004

Zanger, U. M., and Schwab, M. (2013). Cytochrome P450 enzymes in drug metabolism: regulation of gene expression, enzyme activities, and impact of genetic variation. Pharmacol. Ther. 138, 103-141. doi: 10.1016/j.pharmthera.2012.12.007

Zhang, J. J., Zhang, H., Ding, X. L., Ma, S., and Miao, L. Y. (2013). Effect of the P450 oxidoreductase $* 28$ polymorphism on the pharmacokinetics of tacrolimus in Chinese healthy male volunteers. Eur. J. Clin. Pharmacol. 69, 807-812. doi: 10.1007/s00228-012-1432-1

Zhang, X., Li, L., Ding, X., and Kaminsky, L. S. (2011). Identification of cytochrome P450 oxidoreductase gene variants that are significantly associated with the interindividual variations in warfarin maintenance dose. Drug Metab. Dispos. 39, 1433-1439. doi: 10.1124/dmd.111.038836

Conflict of Interest Statement: The authors declare that the research was conducted in the absence of any commercial or financial relationships that could be construed as a potential conflict of interest.

Received: 19 March 2014; accepted: 21 April 2014; published online: 09 May 2014. Citation: Pandey AV and Sproll P (2014) Pharmacogenomics of human P450 oxidoreductase. Front. Pharmacol. 5:103. doi: 10.3389/fphar.2014.00103

This article was submitted to Pharmacogenetics and Pharmacogenomics, a section of the journal Frontiers in Pharmacology.

Copyright (C) 2014 Pandey and Sproll. This is an open-access article distributed under the terms of the Creative Commons Attribution License (CC BY). The use, distribution or reproduction in other forums is permitted, provided the original author(s) or licensor are credited and that the original publication in this journal is cited, in accordance with accepted academic practice. No use, distribution or reproduction is permitted which does not comply with these terms. 